\title{
Criteria for assessing learning material for distance education
}

\author{
J S Wessels \\ University of South Africa
}

\begin{abstract}
This article proposes eight broad criteria for assessing learning material for distance education institutions such as the University of South Africa (Unisa) where learning material in print format is the main teaching method. To this end, the article analyses and evaluates the major trends in the international and national fields of learning and appraises the main elements of a typical learner profile. The criteria have implications for, inter alia, the accessibility and relevancy of learning material, the language of tuition, the intended outcomes of the learning process, the responsiveness of learning material to societal interests and needs, the quality of learning, race and gender issues, and assessment strategies.
\end{abstract}

\section{INTRODUCTION}

$\mathrm{V}$

arious academic departments at universities are engaged in an ongoing process of reviewing curcurricula in order to meet the challenges of an ever changing environment. Learning material is the main teaching method at an institution for distance education such as the University of South Africa (Unisa). Moreover, it can be regarded as a core element of a curriculum. It is not always clear, however, whether existing, modified or brand new learning material is indeed appropriate and effective. Institutions of higher education need to be accountable for the effectiveness of the learning that is taking place.

The aim of this article is to propose broad criteria for assessing learning material for distance education institutions. To this end, it will analyse and evaluate the major trends in the international and national fields of learning, respectively, and appraise the main elements of a typical learner profile in order to develop criteria for accountable assessment of learning material and the implied teaching methods.

\section{CHANGING PERSPECTIVES AND THEORIES IN THE INTERNATIONAL FIELD OF LEARNING}

During the past decade there have been fundamental changes worldwide in perspectives and theories in the fields of education, training and learning. The origins of these changes have not always been of a purely academic nature (Greenwood \& Robins 1998). Political, economic, social and ideological considerations, such as the need to increase the quality of life of especially the poorer populations of the world, appear to be major driving forces behind new ways of thinking in education and training. An important example is the Social Summit during March 1995 in Copenhagen, under the auspices of the United Nations. During this summit world leaders committed themselves to a programme of action to bring about a poverty-free planet by ensuring that people living in poverty have access to productive resources including education, training, technology, knowledge, information and public services (Hartvelt 1996).

Frank Hartvelt (1996), a Deputy Director attached to the United Nations Development Program, has identified human capacity building as one of the most important steps towards access to productive resources (specifically to earn a living). It has become apparent that the level of human capacity has a direct influence on the competence or ability of people to survive in a constantly changing environment. This observation is confirmed by Beryl Levinger (1996) in her work Critical transitions: human capacity deve/opment across the lifespan as she observes that the process of global restructuring, new technology and new ways in which people are expected to work, make the attainment of high-order skills a sine qua non for long-term employment prospects (Levinger 1996).

It appears from the literature on this subject that the major forces driving changes in the field of education and learning come from outside academic disciplines (Greenwood \& Robins 1998). Apart from the need to eradicate poverty and facilitate human capacity building, other reasons for changes in the field of education and learning may be (Gibbons 1998:2, 38, $39,59)-$ 
- the massification of higher education by allowing more people access to systems of higher education

- the need for relevant learning programmes and course content, which means that universities will play a more explicit and active part in economic development, whether at regional or national levels

- a change in focus whereby subjects will become less academic and more vocational (Greenwood and Robins (1998:412) refer to this as a change of an ideological nature)

- a need for universities to be more accountable to their supporting societies

Changes in the international perspectives and theories in the field of learning are clearly driven by various and divergent forces. Most of these forces seem to emerge from outside the boundaries of traditional subject disciplines and are underpinned by a growing demand for social accountability. These changes are generally characterised by a paradigm shift.

\section{Paradigm shift}

Different authors attach different names to the changes that are bringing about a paradigm shift in the field of education and learning (See Table 1). At the end of 1995, a ground-breaking article by Barr and Tagg (1995:12-25) was published in Change, Journal of the American Association for Higher Learning. In their article titled "From teaching to learning: a new paradigm for undergraduate education", they announced that a "paradigm shift is taking hold in American higher education" - a shift from the so-called traditional "instruction paradigm" to a "learning paradigm" (Barr \& Tagg 1995:13).

Two years earlier, an important article was published by Ortrun Zuber-Skerritt (1993:46-57), at that time an academic lecturing at the University of Queensland. In her article "Improving learning and teaching through action learning and action research", she first distinguishes between two views of learning (at this stage not paradigms), namely the traditional view of learning and action learning. Zuber-Skerritt explained

Table 1

Characteristics of the three categories of paradigm shifts

\begin{tabular}{|c|c|}
\hline Traditional knowledge and learning & New knowledge and learning \\
\hline $\begin{array}{l}\text { Instruction paradigm } \\
\text { - knowledge exists "out there" } \\
\text { - knowledge comes in "chunks" and "bits" delivered } \\
\text { - by instructors } \\
\text { - learning is cumulative and linear } \\
\text { - provides instruction } \\
\text { - offers courses and programmes } \\
\text { - improves the quality of instruction }\end{array}$ & $\begin{array}{l}\text { Learning paradigm } \\
\text { - knowledge exists in each person's mind and is } \\
\text { - shaped by individual experience } \\
\text { - knowledge is constructed, created, and "gotten" } \\
\text { - learning is a nesting and interacting of frameworks } \\
\text { - produces learning } \\
\text { - creates powerful learning environments } \\
\text { - improves the quality of learning }\end{array}$ \\
\hline $\begin{array}{l}\text { Paradigm } 1 \\
\text { - "objective knowledge and truth" } \\
\text { - to be obtained through scientific, empirical-analy- } \\
\text { tical methods } \\
\text { - knowledge transmission from expert to novice }\end{array}$ & $\begin{array}{l}\text { Paradigm } 2 \\
\text { - knowledge: changing forms and content } \\
\text { - learning and teaching: active knowledge acquisi- } \\
\text { tion; reflective understanding } \\
\text { - learners/researchers/lecturers: active seekers and } \\
\text { negotiators of meaning, all being involved in active } \\
\text { construction of knowledge (action learning) }\end{array}$ \\
\hline $\begin{array}{l}\text { Mode } 1 \text { knowledge } \\
\text { - knowledge production that has a disciplinary basis } \\
\text { - disciplinary structures both define what will count } \\
\text { as good science and prescribe what students need } \\
\text { to know if they intend to become scientists }\end{array}$ & $\begin{array}{l}\text { Mode } 2 \text { knowledge } \\
\text { - knowledge production/configuration has a trans- } \\
\text { disciplinary basis } \\
\text { - the context of application and unsolved problems } \\
\text { determines that students should become lifelong } \\
\text { learners } \\
\text { - heterogeneity and organisational diversity } \\
\text { - social accountability } \\
\text { - broadly based system of quality control }\end{array}$ \\
\hline
\end{tabular}


these two views of learning by referring to the two major competing paradigms in the social sciences: the traditional paradigm 1 and the alternative paradigm 2 In the context of the traditional paradigm 1 people are seen as "having a static, analytic conception of knowledge, believing in "objective" knowledge and "truth" to be obtained through scientific, empiricalanalytical methods, and believing in knowledge transmission from expert to novice". In the context of the new, alternative paradigm 2 people are seen as "active seekers and negotiators of meaning ... being involved in active construction of knowledge and experience, believing in changing forms and content of knowledge, and regarding learning and teaching as active knowledge acquisition and reflective understanding of development and evaluation" (ZuberSkerritt 1993:51).

Michael Gibbons, Secretary-General of the Association of Commonwealth Universities distinguishes two types of knowledge, namely Mode 1 knowledge and Mode 2 knowledge (Gibbons 1998:4). According to this distinction. Mode 1 knowledge is a model of knowledge production that has a disciplinary basis while Mode 2 knowledge is a shift to knowledge configuration through interaction with a variety of knowledge producers outside the traditional disciplinary boundaries (Gibbons 1998:i).

According to Gibbons (1998:4), most universities of the world, whether developed or developing, are built around Mode 1 production of knowledge. Disciplinary structures define both what will count as good science and also prescribe what students need to know if they intend to become scientists. As a consequence, undergraduate curricula will be driven by the intellectual development of each discipline or subject field in the sense that academics decide what is essential to teach, the institutions agree and, for the most part, students accept this situation (Gibbons 1998:38).

However, it seems that a certain impatience with regard to disciplinary science is emerging throughout the world. This is illustrated by the formation of transdisciplinary groups, one of the characteristics of Mode 2 knowledge, to solve specific mutual problems. Other characteristics of Mode 2 knowledge are that it is produced in the context of application, its heterogeneity and organisational diversity, its enhancement of social accountability and its more broadly based system of quality control (Gibbons 1998:6).

\section{Sociopolitical implications}

The paradigm shifts in the international learning environment appear to have sociopolitical implications for study material and teaching methods. The literature reveals special emphasis on aspects such as -

- relevancy,

- support of economic development and the civic culture, and

- education across the lifespan.

\section{Relevancy}

If lifelong learning means that student discovery and the construction of knowledge (Barr \& Tagg 1995) must concentrate on real issues and problems under real conditions (Zuber-Skerritt 1993:46) in order to solve specific mutual problems, this means that study material and teaching methods need to enhance relevant learning. Purely from a learning perspective, the feeling of personal significance (the personal dimension of contextual relevancy) is seen as the central factor for developing understanding of learning content and for stimulating "deep learning" (Dahlin 1999:203, 206). It is for that reason that actively engaging with the learning material and discussing it with peers, in other words doing things with the material being learnt, play such an important part in the learning process (Dahlin 1999:203). In the process of assessing teaching or learning material and methods, one may ask whether the material and methods succeed in making the learning content relevant to the specific contexts of the learner.

\section{Support of economic development and a civic culture}

An important result of having learning material and methods concentrate on "real issues" (Zuber-Skerritt 1993:46) may be a substantive contribution to the well-being of society in general. For Gibbons (1998:58) a direct implication of the specific nature of Mode 2 knowledge is that learning material and methods reflect the particular university's active role in the economic development of the particular region or nation and in the development of a civic culture (Gibbons 1998:ii, 38, 58). In other words, Mode 2 learning material and methods are relevant to the specific context in which they are applied. This is an illustration of what Greenwood and Robbins (1998:412) identify as an ideological and not an academic reason for changes in curricula. But why should support of economic development be a criterion for learning material and methods? Perhaps it can be explained as an aspect of higher education institutions' accountability to their supporting society (Gibbons 1998:58).

\section{Education across the lifespan}

A third sociopolitical implication of the paradigm shifts in the international learning environment is that learning material and methods should facilitate learn- 
ing over the course of learners' lifespans. Vermunt (1996:27) argues that, as knowledge per se becomes increasingly redundant, and as it becomes less important which specific domain knowledge someone has acquired, it becomes more important that people acquire skills in thinking activities that make them capable of assimilating new knowledge. Such skills will enable them to deal with the huge amounts of information that they are confronted with in their work. In other words, learning material and methods should teach learners how to learn and how to think independently so that they will become lifelong learners. Levinger (1996) proposes the creation of a new science, partagogy, which has as its primary focus to help individuals to develop the skills and knowledge they need "to access available participation opportunities and create new ones over the course of their lifespans". Partagogy is a science of learning specifically to foster human capacity development opportunities (Levinger 1996). It views human capacity development as a twofold process which involves augmenting the degree to which an individual (1) accesses extant participation opportunities; (2) contributes to the creation of new opportunities. The need for standards for lifelong learning and outcomes of learning material has been identified in a number countries, including some states in the United States of America (Marzano, Pickering \& McTighe 1993:10).

The sociopolitical implications of the paradigm shift point to the demand for relevant study material enabling learners to contribute to the economic development and the civic culture of their region or country, and to be lifelong learners.

\section{Knowledge implications}

It is an open question whether new approaches with regard to knowledge, as well as the transfer, production, discovery or construction of knowledge, should be treated as implications of the major paradigm shifts in the international learning environment, or as points of departure for such changes. In a closed system, both approaches may be acceptable. A review of the three categories of paradigm shifts discussed earlier reveals that their major implications for knowledge essentially relate to what is regarded as a body of knowledge, knowledge production, learning and professional knowledge, each of which is considered below.

The issue of a body of knowledge is closely related to knowledge production. It is clear from references to the traditional learning paradigms or knowledge modes that knowledge production is traditionally regarded as a self-contained, disciplinary activity that takes place in self-sufficient institutions (Gibbons 1998:16, 38). Knowledge production and dissemination are no longer self-contained activities carried out in relative institutional isolation, but take place in a transdisciplinary environment and across the boundaries of self-sufficient institutions (Gibbons 1998:i, 6, 16). The implication is that this type of knowledge production is a collaborative affair through sharing intellectual, financial and physical resources. However, the main reason for the transdisciplinary approach is the fact that knowledge production is aimed at solving complex problems surrounding particular applications. Solutions to complex problems are often not possible when using a single disciplinary approach, whereas the ability to work with complex problems is a key element in transdisciplinary approaches (Gibbons 1998:40). The challenge is therefore to equip learners as knowledge workers who will be able to configure transdisciplinary knowledge that may have been produced anywhere in the world to a wide range of problemsolving applications (Gibbons 1998:61). It is evident that a transdisciplinary approach to knowledge production implies that higher learning should be problem-based, instead of discipline-based. However, universities around the world still appear to be operating around the Mode 1 production of knowledge (Gibbons 1998:52).

\section{Teaching/learning implications}

The shift from instruction to learning does have inevitable implications for the learning or teaching of any academic subject. The fact that control over the learning process seems to be shifting from the lecturer to the learner and that the learner is supposed to become a lifelong learner means that a closer look at the learning process has become necessary. In other words, learning material and learning methods within the framework of the new learning paradigm cannot be the same as learning material and methods within the instruction paradigm. As Vermunt (1996:25) puts it: "Instruction does not lead to learning automatically. The learning activities that students employ determine to a large extent the quality of learning outcomes they achieve."

In an empirical study on learning styles and strategies, Vermunt (1996:32-39) identifies four different styles of learning, namely

- the undirected learning style,

- the reproduction directed learning style,

- the meaning directed learning style, and

- the application directed learning style (Dahlin (1999:197) calls it understanding through "merging with reality").

These learning styles seem to differ from one another in five areas (Vermunt 1996:46):

- the way in which students cognitively process learning contents (Dahlin (1999:202) points out 
that understanding requires activity: relating new information to previous knowledge and connecting facts and weaving bits of knowledge together),

- the way in which students regulate their learning.

- the affective processes that occur during studying (Dahlin (1999:203) finds that the feeling of personal significance is seen as the central factor for development of understanding)

- the mental learning models, and

- the learning orientations of students.

A comparison of the various styles in terms of the five areas are summarised in Table 2.

The research by Vermunt (1996:46) shows the possibility of a progression within a learning style in that it often develops from external to internal regulation. The more experienced and skilled students become in a certain learning style, the more it is executed under internal control. An externally regulated reproduction-directed learning style can change into an internally regulated meaning-directed style. The personal commitment to learning associated with self-directed learning seems to form the basis of what Dahlin (1999:206) calls "deep learning".

The results of these studies point to the importance of discouraging undirected and reproduction-directed learning styles among students and of encouraging meaning-directed and application-directed styles (Vermunt 1996:47). The importance of meaning- directed and application-directed styles is supported by Swedish research on "ways of coming to understand" which found that students who "come to understand" through experiences and mental construction are more capable of merging such understanding with reality (Dahlin 1999:191-207). Meaning-directed and application-directed learning styles which are characterised by mostly self-regulated learning appear to be most consistent with the goals of higher education to educate people who should be able to think, decide and to be independent lifelong learners.

\section{DEMANDS OF A COUNTRY-SPECIFIC SYSTEM FOR HIGHER LEARNING}

Learning material and methods cannot be evaluated from the perspective of changes in the international learning environment alone. Responsiveness to the demands of the specific country's system for higher learning can be regarded as a necessity for effective learning. Within the South African context, the National Qualifications Framework (NQF), the outcomes-based education (OBE) system, the South African Qualifications Authority (SAQA) and the learning needs of the public in general all have a prescriptive impact on higher education curricula in general, and on learning material and teaching methods in particular.

The stipulations of the South African Qualifications

Table 2

Learning according to the various styles and their components

\begin{tabular}{|c|c|c|c|c|}
\hline \multirow{2}{*}{ Components } & \multicolumn{4}{|c|}{ Learning styles } \\
\hline & Undirected & $\begin{array}{l}\text { Reproduction } \\
\text { directed }\end{array}$ & $\begin{array}{l}\text { Meaning } \\
\text { directed }\end{array}$ & $\begin{array}{l}\text { Application } \\
\text { directed }\end{array}$ \\
\hline $\begin{array}{l}\text { Cognitive } \\
\text { processing }\end{array}$ & $\begin{array}{l}\text { Hardly any } \\
\text { processing }\end{array}$ & $\begin{array}{l}\text { Stepwise } \\
\text { processing }\end{array}$ & Deep processing & $\begin{array}{l}\text { Concrete } \\
\text { processing }\end{array}$ \\
\hline $\begin{array}{l}\text { Regulation of } \\
\text { learning }\end{array}$ & Lack of regulation & $\begin{array}{l}\text { Mostly external } \\
\text { regulation }\end{array}$ & $\begin{array}{l}\text { Mostly self- } \\
\text { regulation }\end{array}$ & $\begin{array}{l}\text { Both external and } \\
\text { self-regulation }\end{array}$ \\
\hline $\begin{array}{l}\text { Affective } \\
\text { process }\end{array}$ & $\begin{array}{l}\text { Low self-esteem } \\
\text { Failure } \\
\text { expectations }\end{array}$ & Fear of forgetting & Intrinsic interest & Practical interest \\
\hline $\begin{array}{l}\text { Mental mode of } \\
\text { learning }\end{array}$ & $\begin{array}{l}\text { Cooperation and } \\
\text { being stimulated }\end{array}$ & $\begin{array}{l}\text { Intake of } \\
\text { knowledge }\end{array}$ & $\begin{array}{l}\text { Construction of } \\
\text { knowledge }\end{array}$ & Use of knowledge \\
\hline $\begin{array}{l}\text { Learning } \\
\text { orientation }\end{array}$ & Ambivalent & $\begin{array}{l}\text { Certificate and } \\
\text { self-test oriented }\end{array}$ & Person oriented & Vocation oriented \\
\hline
\end{tabular}

(Vermunt 1996:47) 
Authority Act (South Africa 1995, section 2), clearly indicate that the NQF requires learning material to -

- be aimed at learning achievements that fit into the NQF framework for learning achievements (I)

- be accessible to learners, and to make provision for learner mobility and progression (I)

- bring about improved quality of learning (E)

- accelerate the redress of past unfair discrimination (I)

- contribute to the full personal development of each learner and the social and economic development of the nation at large (I)

When one analyses these objectives of the NQF, it appears that only one of these objectives (improving the quality of learning) can be regarded as purely educational $(E)$, while all others are of a sociopolitical or ideological (I) nature. This observation is also in line with the characteristics of paradigm shifts in the international learning environment. Regardless of individual opinion on the sociopolitical objectives for the learning process, their application in the South African learning environment cannot be neglected.

The NQF objectives that are specifically relevant to learning material and teaching methods are those referring to accessibility, improvement of the quality of learning and the contribution to the development of the learner (personally) and the nation in general An analysis of official documents (South Africa 1996a; South Africa 1997a; South African Qualifications Authority 1997b) reveals the following OBE implications for curricula, and more specifically learning material and teaching methods, in South Africa:

- The starting point for the learning process is the intended outputs or significant exit level outcomes which have a defined purpose or purposes, instead of the inputs of traditional curriculum-driven education and training. That means that all the curriculum processes, such as curriculum design, material, teaching methods and assessment, will be defined, derived, developed, and organised according the intended outcome of the learning process

- The end products of a learning process are outcomes. These outcomes include everything that has been learnt, incorporating social and personal skills, learning how to learn, concepts, knowledge, understanding, methodologies, values, attitudes and so on, and including both intended and unintended outcomes.

- The control over the learning process is shifting from the teacher to the learner

- There is a focus on the achievement of clearly defined outcomes as opposed to syllabus content only.

- Increased and broadened participation is provided to accommodate a larger and more diverse student population.

- Responsiveness to societal interests and needs is evident in order to address national needs and to participate in a rapidly changing and competitive global context.

- Cooperation and partnerships in governance are established to create an enabling institutional environment and culture that are sensitive to and affirm diversity, promote reconciliation and respect for human life, protect the dignity of individuals from racial and sexual harassment, and reject all other forms of violent behaviour.

- As there is a need for national initiatives to facilitate and support institutional and regional capacity-building programmes, partnerships will be required between higher education institutions, NGOs, the private sector and international agencies, with support from the government.

I believe that the way in which Killen and Spady (1999:204) have combined the twelve SAQA outcomes into an OBE Curriculum design matrix is the best way of providing learners with a holistic learning experience. With regard to their matrix, one can use the following questions as assessment criteria for learning material:

- Which life roles of the learner can be regarded as critical in this specific learning situation?

- Does the learning material make provision for learning in the relevant life roles of the learner?

- To what extent does the learning material make provision for learning experiences to acquire those abilities (essential knowledge, technical skills, interpersonal skills, management skills, professionalism and life orientation) essential to the successful performance of the life roles?

\section{LEARNER PROFILE}

A major consequence of the paradigm shift in the field of education and learning is that it has rightfully moved the learner into a central position in the learning process. This clearly coincides with the international trend of massification of higher education, which has changed the profile of the typical learner or student.

One of the important findings of the research on learning styles by Vermunt (1996:46) is that learners' experiences and levels of skill have implications for the regulation of the learning process provided by the learning material. It seems that self-directed learning, which according to Dahlin (1999) forms the basis of "deep learning", is likely to be the learning style of mature learners. The level of maturity will most probably be related to the age of learners and their previous qualifications or prior learning. Deep learning also appears to be associated with the relevancy of the learning experience for the learner, in other 
words, whether the learning experience is related to the learner's various life roles (eg occupational role, civic role and role as lifelong learner). However, what remains decisive in any learning (whether it is superficial learning or deep learning) is the accessibility of the learning process. In other words, do the offerings of learning reach the potential learners, and if so, do the learners understand the language of tuition? Bearing that in mind, as well as the various criteria for effective learning material deduced from the international and national learning environments, the question that arises is: What does the learner and his or her context look like?

\section{In other words -}

- how old is the average learner and is the learning material relevant to the specific age group of most of the learners?

- what is the learner's home language, and does the average learner understand the language in which the learning material has been written

- can the learners' racial and gender profiles be regarded as a true reflection of that of the country's population and does the learning material show a sensitivity to race and gender issues in order not to offend people from the various groups?

- what type of prior qualifications do learners have, and does the learning material simultaneously make provision for those learners who have enrolled without full exemption on the one hand, and for those who enrolled with full exemption on the other hand?

- what are the learners' occupations and is the learning material relevant to the occupations of the majority of learners?

- where in the country or the world do the learners live and is the learning material relevant to the civic context of the learners?

\section{CONCLUSION}

Many academic departments have revised their curricula, developed new learning material and changed their teaching methods. The decisive question is whether all these changes have brought about effective learning in order to increase the quality of life of learners.

Eight criteria have been deduced from the preceding analysis of the changing perspectives and theories in the international field of learning, the demands of a country-specific learning system, and a specific learner profile, and are proposed to form the basis of a possible assessment instrument which can be adapted to the specific circumstances of a country, region or university. These criteria are the following:

1 Is the material accessible to learners? In other words: Does the material take cognisance of the learner's level of school education or prior learning?
2 Does the average learner understand the language in which the learning material has been written?

3 Is the material designed according to the intended outcome of the learning process?

4 Is the learning material relevant to the specific context of the learners? In other words, does the material -

- make provision for learning experiences essential to successful performance in the various life roles of the learner?

- enhance the learning of competencies required to perform the duties associated with a specific level in a profession, occupation or career?

- encourage meaning-directed and applicationdirected learning instead of undirected or reproduction-directed learning?

- connect to learners' own experiences and reality to create personal relevancy?

- have relevancy to the specific age group of the majority of the learners?

- have a problem-based approach, instead of discipline-based approach?

5 Is the material responsive to societal interests and needs, and does it equip the learners with competencies to make a positive impact on the economic and civic well-being of society?

6 Does the material improve the learners' quality of learning by -

- equipping the learners with competencies to learn and to think independently?

- shifting the control over learning, from the lecturer to the learner in accordance with the learner's growing learning abilities?

- equipping learners as knowledge workers who will be able to coherently construct, modify, configure and utilise transdisciplinary knowledge in relation to a wide range of problemsolving applications?

7 Does the learning material show a sensitivity to race and gender issues in order to nurture a respect and tolerance for otherness?

8 Does the material make provision for assessment strategies (assignments, self-evaluation activities and examination) that will give learners the opportunity to demonstrate their understanding. and to thoughtfully apply their competencies in a variety of contexts?

Institutions of higher education must be held accountable for the effectiveness of the learning material used for distance education. An appropriate means would be to hold academic departments responsible for ensuring that learning material is assessed in an accountable manner. The eight criteria listed above may be useful for such an assessment. 


\section{REFERENCES}

Barr, R B \& Tagg, J 1995. From teaching to learning: a new paradigm for undergraduate education. Change: The Magazine of Higher Learning 27(6):12-25, November/December.

Clapper, VA \& Wessels, J S 1996. Transforming the curriculum for Public Administration at Unisa. SAIPA Journal of Public Administration 32(1):43-64.

Dahlin, B 1999. Ways of coming to understand: metacognitive awareness among first-year university students. Scandinavian Journal of Educational Research 43(2):191-207.

Gibbons, M 1998. Higher education relevance in the $21^{\text {st }}$ century. The World Bank Education.

Greenwood, J \& Robins, L 1998. Public administration curriculum development in Britain: outsider or insider influence? International Review of Administrative Sciences 64(3):409-421.

Killen, R \& Spady, W 1999. Using the SAQA critical outcomes to inform curriculum planning in higher education in South Africa. South African Journal of Higher Education 13(2):200-208.

Levinger, B 1996. Critical transitions: human capacity development across the lifespan. Newton, USA: Education Development Centre. Available online at URL: http://www.edc.org/INT/HCD/crittrans.htm.

Marzano, R J, Pickering, D \& McTighe, J 1993. Assessing student outcomes: performance assessment using the dimensions of learning model. Alexandria, Virginia: ASCD.

Schön, D A 1995. The new scholarship requires a new epistemology: knowing-in-action. Change: The Magazine of Higher Learning 27(6):26-39, November/December.

South Africa 1995. South African Qualifications Authority Act, 58 of 1995.

South Africa 1996a. Ministerial Committee for Development Work on the NQF. Lifelong learning through a national qualifications framework: discussion document. Pretoria: Department of Education.

South Africa 1996b. South African Qualifications Authority (SAQA), decision 0204/96. Available online at URL: http://www.sqa.org.za/docs.main.html.

South Africa 1997a. Education White Paper 3: A programme for the transformation of higher education. Government Notice 1196 of 1997. Pretoria: Department of Education.

South Africa 1997b. White Paper: Public service training and education. Available online at URL: http://saqa.org.za/docs/main.html (downloaded 11/6/1999)

South African Qualifications Authority 1997a. Criteria for the registration of qualifications. SAQA Bulletin $9(1): 15-18$.

South African Qualifications Authority 1997b. The emergence of the NQF and SAQA. SAQA Bulletin 1(1):2-4.

South African Qualifications Authority 1997c. Proceedings and decisions of the SAQA. SAQA Bulletin 1(1):5-10.

University of South Africa (Unisa) 2000. Bureau for Management Information. Student Statistics: 1990-2000.

Vermunt, J D 1996. Metacognitive, cognitive and affective aspects of learning styles and strategies: a phenomenographic analysis. Higher Education 31:25-50.

Unisa 2000. Bureau for Management Information. Pretoria: University of South Africa.

Zuber-Skerritt, O 1993. Improving learning and teaching through action learning and action research. Higher Education Research and Development 12(1):46-57.

Zuber-Skerritt, O 1995. Models for action research, in Pinchen, S \& Passfield, R (eds) Moving on: creative applications of action learning and action research. Brisbane: ALARPM:3-29. 